\title{
Immunochromatographic and microscopic detection of Plasmodium falciparum in recipients of $P$. falciparum-infected donor blood
}

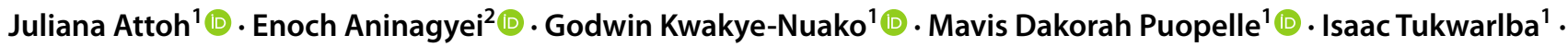 \\ Justice Afrifa ${ }^{3}$. Desmond Omane Acheampong ${ }^{1}$ (1)
}

Received: 1 November 2021 / Accepted: 21 February 2022 / Published online: 1 March 2022

(c) The Author(s), under exclusive licence to Springer-Verlag GmbH Germany, part of Springer Nature 2022

\begin{abstract}
Blood transfusion practice is an essential medical intervention; however, it poses problems of transmissibility of infectious diseases including malaria. This study was designed to determine the potential of transfusion-transmitted malaria (TTM) by detecting malaria antigens and parasites in recipients of infected donor blood. After successful blood transfusion, remnants of transfused blood were screened for Plasmodium falciparum HRP2 antigen and parasitemia using CareStart malaria RDT and $10 \%$ Giemsa stain microscopy respectively according to established protocols. Recipients of microscopy detectable P. falciparum in infected blood who tested negative for malaria by both microscopy and mRDT prior to receiving infected donor blood were followed up weekly for 35 days. Donor P. falciparum antigenemia and parasitemia were $12.1 \%$ and $8.4 \%$, respectively, while the prevalence of blood recipient parasitemia was 3.2\%. Blood stored for 2-5 days recorded mean parasitemia higher than those stored for a day and after 5 days. Additionally, parasitemia was observed in all follow-up days with marginally high frequencies in days 7, 14, and 35. There was no association between the attributes (storage days, blood group, and parasite count range) of the infected donor blood units and the characteristics of blood recipients with post-transfusion parasitemia. This study provides baseline data on TTM in Ghana. However, further studies should establish the genetic relatedness of the implicated parasites since new infections and/or recrudescence of previous infections could account for this observation.
\end{abstract}

Keywords Transfusion-transmitted malaria $\cdot$ Plasmodium falciparum $\cdot$ Blood recipients $\cdot$ Malaria $\cdot$ Post-transfusion parasitemia

Section Editor: Tobili Sam-Yellowe

Enoch Aninagyei

eaninagyei@uhas.edu.gh

$\triangle$ Desmond Omane Acheampong dacheampong@ucc.edu.gh

1 Department of Biomedical Sciences, School of Allied Health Sciences, University of Cape Coast, Cape Coast, Ghana

2 Department of Biomedical Sciences, School of Basic and Biomedical Sciences, University of Health and Allied Sciences, Ho, Volta Region, Ghana

3 Department of Medical Laboratory Sciences, School of Allied Health Sciences, University of Cape Coast, Cape Coast, Ghana

\section{Background}

Malaria, a tropical disease caused by the protozoan intracellular Plasmodium parasite, is a major cause of morbidity and mortality especially in malaria endemic countries in sub-Saharan Africa and South East Asia (Dhiman 2019). Human malaria is caused by five different species of the Plasmodium parasite, namely, Plasmodium falciparum, $P$. vivax, P. malariae, P. ovale, and P. knowlesi (WHO 2018). P. falciparum is mainly transmitted from an infected human to another through the bite of the female Anopheles mosquito (Cox 2010); however, transmission through infected donor blood has not been discounted.

Blood transfusion practice is a very essential medical intervention meant to save life through replacing vital blood components in a patient that lacks them (Jersild and Hafner 2017). Notwithstanding, transfused blood may contain malaria parasites especially $P$. falciparum; hence, blood banks, especially in malaria endemic countries, are expected 
to screen for $P$. falciparum in blood donors. However, this recommendation by several authors is not being adhered to (Abdullah and Karunamoorthi 2016; Antwi-Baffour et al. 2019; Aninagyei et al. 2020b; Tsehay et al. 2020). Due to this gap in blood transfusion practice, several studies have reported varying prevalence rates of Plasmodium sp. infection in either prospective blood donors or donor blood units, across the world (Owusu-Ofori et al. 2016; Oladeinde et al. 2014; Alemu and Mama 2018). P. falciparum, P. vivax, $P$. malariae, and $P$. ovale have been detected in blood donors, hence implicated in transfusion-transmitted malaria (TTM) (Kitchen et al. 2005). These blood donors are most likely to harbor these malaria parasites, albeit at low densities (Faruk et al. 2017), which could later be transfused to patients, who may require transfusion. Most blood transfusion recipients, including pregnant women, children under 5 years of age, and immunocompromised patients, are vulnerable and susceptible to severe forms of any infection, including $P$. falciparum, hence at higher risk of TTM.

Refrigeration of P. falciparum-infected donor blood has not been found to render the unit of blood sterile since the parasite has been shown to survive refrigeration for up to 14 days at $4{ }^{\circ} \mathrm{C}$ (Chattopadhyay et al. 2011). For this reason, the parasite could establish an infection in a recipient of such infected blood, if the recipient had no or partial immunity to the parasite (Ademolue and Awandare 2018). Notwithstanding, there is limited data in this regard. Therefore, this study was designed to determine the proportion of recipients of donor blood units contaminated with microscopically detectable $P$. falciparum that developed malaria parasitemia within 35 days of receiving such unit(s) of donor blood and to determine the attributes, namely, storage days, blood group, and parasite count range, of donor blood units that resulted in recipient parasitemia on follow-up testing.

\section{Methods}

\section{Study design and study area}

This study experimented the transmissibility of malaria parasites through unintentional receipt of $P$. falciparum-infected donor blood. The study was conducted at Nsawam Government Hospital (NGH) in the Eastern region of Ghana. NGH is a 135-bed capacity hospital with 24-h service delivery. The hospital has all vital clinical units, namely, diagnostic units, wards, theaters, and public health units. The hospital performs an average of 823 blood transfusions yearly. Blood is collected by an in-house blood donation team. Most of the blood donors are family replacement donors with few voluntary donors. Majority of blood transfusions are in the form of whole blood while concentrated red cell transfusions are in the minority. Blood donors are screened for hepatitis
B virus, hepatitis $\mathrm{C}$ virus, HIV, and Treponema pallidum. As the practice in Ghana, blood donors and donor blood units are not screened for malaria parasites (Aninagyei et al. 2021).

\section{Experimental design}

Consent was sought from each patient being prepared for blood transfusion to be recruited into the study. Subsequently, a maximum of $3 \mathrm{~mL}$ of blood was collected from the patient, and in cases of patients less than 5 years, $1 \mathrm{~mL}$ of blood was collected. Immediately after completion of the blood transfusion, the blood bag was collected. At least $3 \mathrm{~mL}$ of the remaining blood in the blood bag was drained into a plain tube. Malaria parasites were detected using both malaria rapid diagnostic test kit (mRDT) and microscopy, in both post-transfusion donor blood and pre-transfusion recipient blood samples. A patient that tested negative for malaria by both microscopy and mRDT but received malaria parasite-infected donor blood was followed up to 35 days post-transfusion (days 2, 7, 14, 21, 28, and 35).

\section{Sources of donor blood used in this study}

All donor blood used in this study was collected by the inhouse static blood bank from August 2020 to May 2021.

\section{Weight-to-volume conversion of donor blood}

The weight of each donor blood was taken with a blood bank scale (Lasany, India; sensitivity $=0.1 \mathrm{~g}$ ). Weight in grams $(\mathrm{g})$ was converted to volume in milliliters $(\mathrm{mL})$ assuming the density of blood was approximately $1 \mathrm{~g} / \mathrm{mL}$ (Vitello et al. 2015).

\section{Donor blood sample size determination}

Due to the unavailability of the specific prevalence of malaria parasites in the Eastern Region of Ghana, the prevalence was estimated as $50 \%$. Using the formula, $n=z^{2} p(1-p) / d^{2}$, where $n=$ sample size, $p=$ proportion of blood donors with malaria, $1-p=$ proportion of blood donors without malaria, $z=$ confidence level at $95 \%$ (standard value of 1.96), and $d=$ margin of error at $5 \%$ (standard value of 0.05 ), the minimum sample size was estimated as 384 .

\section{Inclusion and exclusion criteria}

Donor blood units included in this study were blood units that were bled at NGH and have been stored at $4{ }^{\circ} \mathrm{C}$ for not less than $24 \mathrm{~h}$. All donor blood units collected outside NGH were excluded from this study. To be included in this study, a blood recipient or an accompanying relative must 
give consent. A blood recipient needed to be transfused with more than half of the unit to be qualified to be included in the study. To be qualified to be followed up after discharge, a blood recipient must test negative for malaria by both mRDT and microscopy and must have received donor blood with microscopy detectable malaria parasites. Additionally, a recipient that was unwilling to provide accurate details of place of residence as well as demographic and clinical information was excluded. Finally, a blood recipient whose residence was further than $30 \mathrm{~km}$ from Nsawam township was excluded from the study.

\section{Blood recipient demographic and clinical information}

On the day of discharge, the following information was collected from the infected blood recipient: age, gender, marital status, employment status, accurate description of place of residence (including GhanaPost address, landmarks, telephone number of the recipient and at least one relative) and clinical history necessitating the transfusion. Body temperature was taken before final discharge. Blood groups of recipients were retrieved from their clinical records.

\section{Residence verification of the infected blood recipient}

On the discharge day, a member of the research team accompanied the recipient home. The digital address of the place was taken using the GhanaPost digital address application. Additionally, Google map coordinates were also taken. All immovable landmarks were taken note of as well as the telephone numbers of relatives of the recipients. This follow-up strategy has previously been used (Aninagyei et al. 2020a).

\section{Detection of malaria parasites using mRDT and microscopy}

Serologically, Plasmodium falciparum malaria parasites were detected using CareStart mRDT (Access Bio, Somerset, USA). Testing was done according to the manufacturer's protocol. Malaria parasitaemia was determined using $10 \%$ Giemsa staining; sample with parasitemia was quantified as previously published (Aninagyei et al. 2021). This was done for both the remainders of transfused blood and pretransfusion recipient blood.

\section{Follow-up on recipients of malaria-infected blood}

Recipient of malaria-infected donor blood was followed up on days $2,7,14,21,28$, and 35 . On each day of followup, a member of the research team visited the residence of the recipient. Using aseptic means and ensuring maximum protection against SARS-CoV-2, at most $100 \mu \mathrm{L}$ whole blood was collected into pediatric EDTA tubes. Temperature was taken using noncontact infra-red thermometer. As soon as $P$. falciparum was detected by both mRDT and microscopy, recipient follow-ups were ceased. All infected posttransfusion individuals were referred to the nearest health facility for malaria management.

\section{Statistical analysis}

Data were analyzed using descriptive statistics. The prevalence of donor malaria antigenemia and parasitemia was determined using the total donor blood analyzed in the study as the denominator. Characteristics of blood recipients transfused with different quanta of donor blood parasitemia were determined by using cross-tabulation to point out the various variables of infected blood recipients (age, gender, blood group, and clinical conditions necessitating donation) that receive different parasitemia (using a range of 199 million parasites per donor unit). The parasitological outcome of the follow-up was also analyzed by determining the recipient variables (age range in years, gender, blood group, follow-up period, and clinical condition of the blood recipient) associated with positive mRDT and microscopy during follow-up. Finally, the characteristics of the infected donor blood units (storage days blood group and estimated total parasitemia) that resulted in recipient follow-up parasitemia were also analyzed.

\section{Results}

\section{Characteristics and prevalence of $P$. falciparum antigenemia and parasitemia in donor blood by blood type and storage days}

Overall, 571 remainders of transfused donor blood units were collected during the study. Of this total, the majority of the donor blood was blood group O Rh D positive (294/571), whereas blood group A negative was minority group (8/571). No donor blood was of AB negative blood type. In all, $P$. falciparum HRP2 antigenemia was observed in 69 (12.1\%) donor blood units, whereas parasitemia was observed in 48 (8.4\%) donor blood units. P. falciparum antigenemia and parasitemia were observed in all blood types, although at varying frequencies, except blood type A negative. In all cases, $P$. falciparum microscopy agreed with $P$. falciparum HRP2 antigenemia. Twenty-four (68.6\%) of the 35 donor blood units of blood group $\mathrm{O}$ positive blood type were positive by microscopy. Regarding blood group A positive, 9 (75\%) of the 12 donor units with P. falciparum antigenemia were positive microscopically. Similarly, 7 (58.3\%) of the 12 of the donor blood type B positive with P. falciparum 
antigenemia were positive by microscopy. All numbers of donor blood units with blood groups $\mathrm{O}$ negative and $\mathrm{B}$ negative to $P$. falciparum antigenemia were positive microscopically. Majority of donor blood units were whole blood (92.5\%); the rest were concentrated red blood cells. The prevalence of $P$. falciparum antigenemia and parasitemia in the whole blood units was $62(10.9 \%)$ and $45(7.9 \%)$, respectively. The prevalence was lower in concentrated red blood cells, where $7(1.2 \%)$ and $3(0.5 \%)$ P. falciparum antigenemia and parasitemia were found, respectively. Over $90 \%$ (528/571) of the donor blood units were banked for just one day. While 83 (14.5\%) donor units were banked for between 2 - 5 days, 36 (6.3\%) donor units were banked for more than 5 days. Prevalence of $P$. falciparum antigenemia and parasitemia in donor blood stored for 1 day was $9.1 \%$ and $6.5 \%$ respectively. Blood banking for $2-5$ days yielded a prevalence of $1.9 \%$ and $1.2 \%$ for P. falciparum antigenemia and parasitemia, respectively. P. falciparum antigenemia and parasitemia prevalence reduced with prolonged storage. $P$. falciparum parasitemia was not detected after 18 days of storage (Table 1).

\section{Characteristics of donor blood units with microscopy detectable malaria parasitemia}

From Table 2, it was observed that infected blood group A positive carried the highest number of malaria parasites with an estimated mean parasitemia of $1,058,374,028$ parasites/
Table 1 Prevalence of Plasmodium falciparum infection in donor blood

\begin{tabular}{|c|c|c|c|c|}
\hline & \multicolumn{2}{|l|}{ mRDT } & \multicolumn{2}{|l|}{ Microscopy } \\
\hline & $\begin{array}{l}\text { Positive } \\
n=69(12.1 \%)\end{array}$ & $\begin{array}{l}\text { Negative } \\
n=502(87.9 \%)\end{array}$ & $\begin{array}{l}\text { Positive } \\
n=48(8.4 \%)\end{array}$ & $\begin{array}{l}\text { Negative } \\
n=523(91.6 \%)\end{array}$ \\
\hline \multicolumn{5}{|l|}{ Blood group } \\
\hline O Rh D positive $(n=294)$ & $35(6.1 \%)$ & $259(45.4 \%)$ & $24(4.2 \%)$ & $270(47.3 \%)$ \\
\hline O Rh D negative $(n=10)$ & $4(0.7 \%)$ & $6(1.1 \%)$ & $4(0.7 \%)$ & $6(1.1 \%)$ \\
\hline A Rh D positive $(n=115)$ & $12(2.1 \%)$ & $103(18.0 \%)$ & $9(1.6 \%)$ & $106(18.6 \%)$ \\
\hline A Rh D negative $(n=8)$ & $0(0.0 \%)$ & $8(1.4 \%)$ & $0(0.0 \%)$ & $8(1.4 \%)$ \\
\hline B Rh D positive $(n=120)$ & $12(2.1 \%)$ & $108(18.9 \%)$ & $7(1.2 \%)$ & $113(19.8 \%)$ \\
\hline B Rh D negative $(n=9)$ & $1(0.2 \%)$ & $8(1.4 \%)$ & $1(0.2 \%)$ & $8(1.4 \%)$ \\
\hline AB Rh D positive $(n=15)$ & $5(0.9 \%)$ & $10(1.8 \%)$ & $3(0.5 \%)$ & $12(2.1 \%)$ \\
\hline AB Rh D negative $(n=0)$ & $0(0.0 \%)$ & $0(0.0 \%)$ & $0(0.0 \%)$ & $0(0.0 \%)$ \\
\hline \multicolumn{5}{|l|}{ Type of product } \\
\hline Whole blood $(n=528)$ & $62(10.8 \%)$ & $466(81.6 \%)$ & $45(7.9 \%)$ & $483(84.6 \%)$ \\
\hline CRBC $(n=43)$ & $7(1.2 \%)$ & $36(6.3 \%)$ & $3(0.5 \%)$ & $40(7.0 \%)$ \\
\hline \multicolumn{5}{|l|}{ Days in storage } \\
\hline $1(n=452)$ & $52(9.1 \%)$ & $400(70.0 \%)$ & $37(6.5 \%)$ & $415(72.7 \%)$ \\
\hline $2-5(n=83)$ & $11(1.9 \%)$ & $72(12.6 \%)$ & $7(1.2 \%)$ & $76(13.3 \%)$ \\
\hline $6-9(n=15)$ & $2(0.4 \%)$ & $13(2.3 \%)$ & $2(0.4 \%)$ & $13(2.3 \%)$ \\
\hline $10-13(n=10)$ & $1(0.2 \%)$ & $9(1.6 \%)$ & $1(0.2 \%)$ & $9(1.6 \%)$ \\
\hline $14-17(n=4)$ & $2(0.4 \%)$ & $2(0.4 \%)$ & $1(0.2 \%)$ & $3(0.5 \%)$ \\
\hline$>18(n=7)$ & $1(0.2 \%)$ & $6(1.1 \%)$ & $0(0.0 \%)$ & $7(1.2 \%)$ \\
\hline
\end{tabular}

$m R D T$, malaria rapid diagnostic testing; $C R B C$, concentrated red blood cells

Table 2 Estimated $P$. falciparum parasitemia per unit of blood transfused

\begin{tabular}{llllll}
\hline Blood group & $\begin{array}{l}\text { Number of } \\
\text { donor units }\end{array}$ & $\begin{array}{l}\text { Mean weight }(\mathrm{g}) \text { of } \\
\text { donor blood }\end{array}$ & $\begin{array}{l}\text { Mean estimated volume }(\mu \mathrm{L}) \text { of } \\
\text { donor blood transfused }\end{array}$ & $\begin{array}{l}\text { Mean para- } \\
\text { sitemia }(/ \mu \mathrm{L})\end{array}$ & $\begin{array}{l}\text { Total mean estimated malaria } \\
\text { parasite load per unit of blood }\end{array}$ \\
\hline O Rh D positive & 24 & 410.2 & $410,229.1$ & 1858 & $764,867,704$ \\
O Rh D negative & 4 & 415.2 & $415,175.3$ & 1123 & $472,942,025$ \\
A Rh D positive & 9 & 388.8 & $388,822.2$ & 2722 & $1,058,374,028$ \\
B Rh D positive & 7 & 370.5 & $370,499.9$ & 962 & $376,359,514$ \\
B Rh D negative & 1 & 385.1 & $385,199.8$ & 580 & $223,358,000$ \\
AB Rh D positive & 3 & 274.9 & $274,933.0$ & 750 & $209,666,067$ \\
\hline
\end{tabular}

${ }^{1}$ Weight-to-volume conversion based on the specific gravity of blood being approximately $1 \mathrm{~g} / \mathrm{mL}$ (Vitello et al. 2015) 
unit of donor blood. This was followed by blood group $\mathrm{O}$ positive with an estimated parasitemia of $764,867,704$ parasites/unit of donor blood. The rest of the blood group contained between 500 and 250 million parasites/unit of donor blood, while blood group $\mathrm{AB}$ positive contained the least parasitemia with an estimated count of 209,666,067 parasites/unit of donor blood.

\section{Characteristics of blood recipients in Nsawam Government Hospital during the study period}

In all, 440 blood recipients received 571 donor blood units. Of these blood recipients, 366 (83.2\%), 50 (11.4\%), 17 (3.9\%), $5(1.1 \%)$, and $2(0.4 \%)$ received one, two, three, four, and five unit(s) of blood respectively. The age range of the blood recipient was 1 month, 4 days to 83 years. The modal age range was $21-30$ years (Fig. 1A). Female blood recipients were disproportionally high (85.68\%) (Fig. 1B). More than half of the recipients were married (56.59\%) while $12.5 \%$ of the blood recipients were below marital age ( $\leq 18$ years) (Fig. 1C). Additionally, the majority of the recipients were petty traders $(32.72 \%)$ while pensioners were in the minority ( $0.45 \%)$ (Fig. 1D). The blood recipients received blood for various reasons; $379(86.14 \%)$, $55(12.5 \%)$, and $6(1.36 \%)$ were transfused on account of anemia, hemorrhage, and fetal distress respectively. The blood recipients were hospitalized between 1 and 21 days; a little over $92 \%$ of them were hospitalized between 1 and 3 days while the rest (approx. 8\%) were hospitalized up to 21 days. Furthermore, the majority of the recipients were blood group O positive (47.95\%), whereas only one $(0.23 \%)$ of the recipients was blood group AB negative. Finally, almost all recipients were normothermic (mean temperature $=36.54 \%)($ Table 3$)$.

\section{Different recipients received different quantities of $P$. falciparum-infected donor blood}

Forty-eight blood recipients received donor blood with microscopically detected $P$. falciparum. Of this number, only one received malaria parasites less than 99 million parasites per donor unit. This blood was transfused to a 2-month-old baby with anemia with blood group AB. Additionally, 17 (35.4\%) received an estimated 100-299 million parasites per unit of blood. These recipients were females with the majority being of blood group $\mathrm{O}$ with over $70 \%$ of them being anemic. Furthermore, 14 (29.2\%) of the recipients received donor blood with parasitemia between 300 and 499 million parasites per donor blood. Both males (21.4\%) and females (78.6\%), with mean age 29 years, of which most were

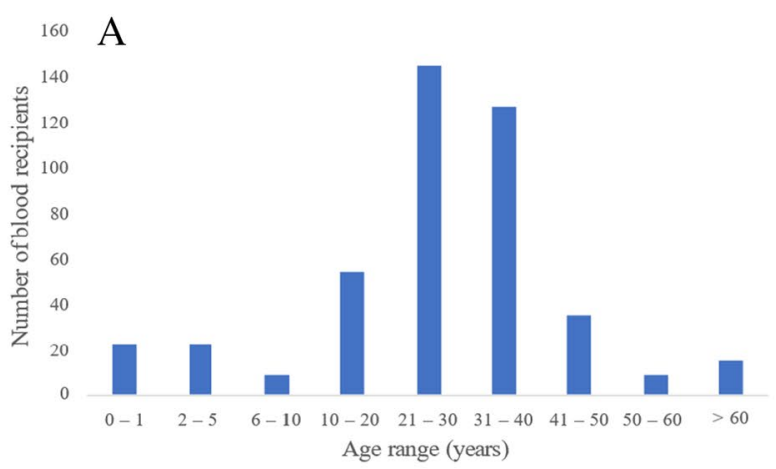

C

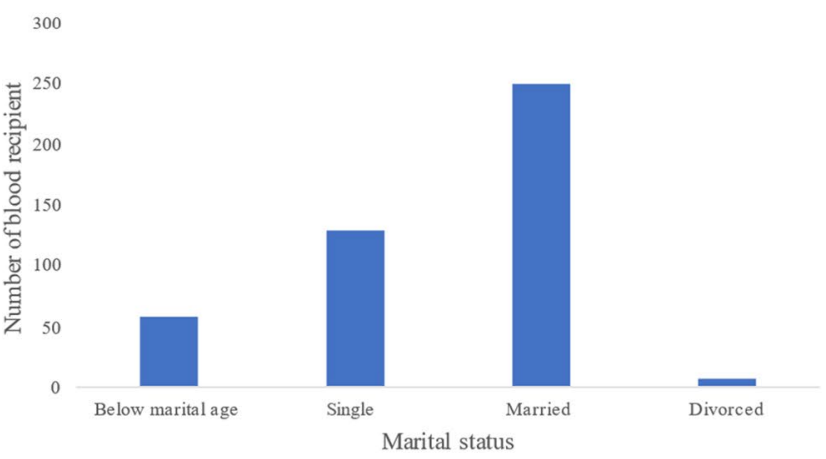

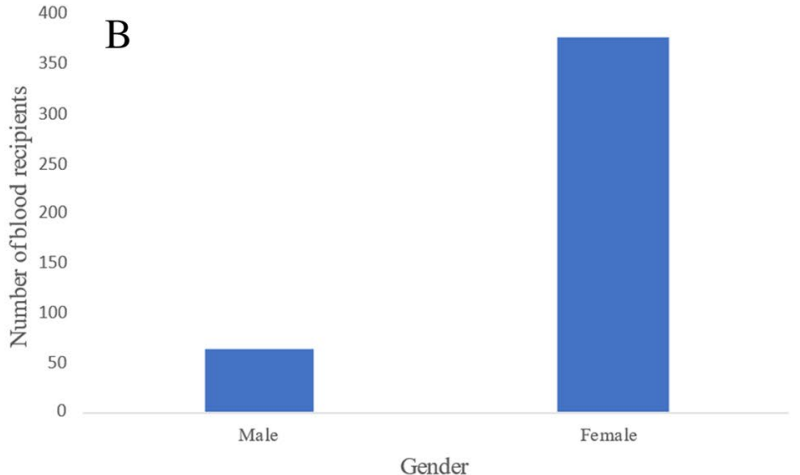

$\mathrm{D}$

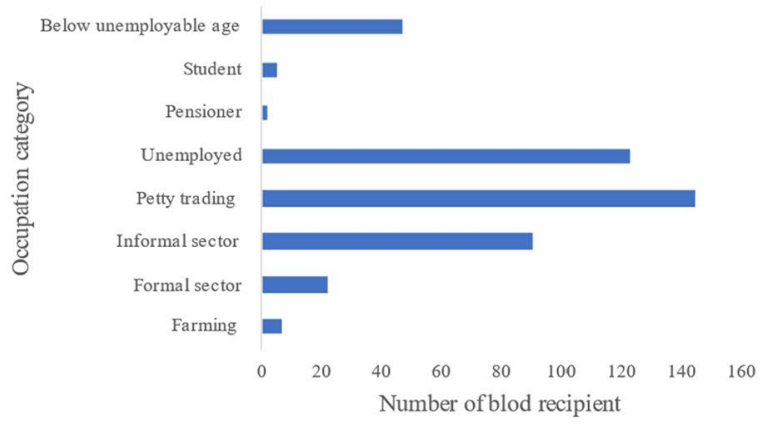

Fig. 1 Demographic characteristics of the blood recipients. Distribution of age range (A), gender distribution (B), marital status distribution (C), occupation category (D) 
Table 3 Clinical characteristics of the recipients of donor blood

\begin{tabular}{lll}
\hline Variables & $\begin{array}{l}\text { Number of blood } \\
\text { recipients } \\
(n=440)\end{array}$ & Percentage \\
\hline Clinical condition classification & 379 & \\
Anemia $^{1}$ & 55 & 86.1 \\
Hemorrhage $^{2}$ & 6 & $12 . .5$ \\
Fetal distress $^{3}$ & & 1.4 \\
Number of days on admission & 405 & \\
1-3 & 15 & 92.1 \\
4-6 & 4 & $3 . .4$ \\
7-9 & 16 & 0.9 \\
$>10$ & 36.54 & 3.6 \\
Mean temperature $\left({ }^{\circ}\right.$ C) & & \\
Blood group & 211 & 48.0 \\
O Rh D positive & 7 & 1.6 \\
O Rh D negative & 93 & 21.1 \\
A Rh D positive & 7 & 1.6 \\
A Rh D negative & 97 & 22.1 \\
B Rh D positive & 7 & 1.6 \\
B Rh D negative & 17 & 3.9 \\
AB Rh D positive & 1 & 0.2 \\
AB Rh D negative & & \\
\hline & &
\end{tabular}

${ }^{1}$ Anemia (moderate anemia, hemoglobin level 8-11 g/dL $(n=330)$; severe anemia $<8 \mathrm{~g} / \mathrm{dL}(n=49)) .{ }^{2}$ Hemorrhage (cesarian section $n=21$, myomectomy $n=19$, ectopic $n=12$, hernia surgery $n=1$, pile bleeding $n=1$, prolonged labor $n=1$ ). ${ }^{3}$ Fetal distress (oligohydramnios $n=3$, cord prolapse $n=2$, intra-uterine fetal death $n=1$ )

anemic (64.3\%), received such blood. Six recipients received blood with parasitemia 500-699 million parasites, with most of them being females (83.3\%), blood group O (50\%), and anemic $(83.3 \%)$. Two males and one female were transfused with blood of parasitemia 700-899 million parasites. Transfusion was on account of anemia (66.7\%). Finally, seven female recipients received blood of parasitemia $>900$ million parasites. Most of these recipients were blood group A on account of anemia (100\%) (Table 4).

\section{Parasitological outcome of follow-up of recipients of infected blood}

Of the 48 recipients of microscopically detected P. falciparum in the donor blood units, follow-up was completed for $40(83.3 \%)$ of them with eight of them being lost to follow-up. Both mRDT and microscopy were positive for 14 of the 40 successfully followed up recipients, while only mRDT was positive in nine follow-up recipients (Table 4). Among all variables assessed for recipient follow-up parasitemia, both mRDT and microscopy did not detect respectively $P$. falciparum antigenemia and parasitemia in recipients aged less than 1 year, between

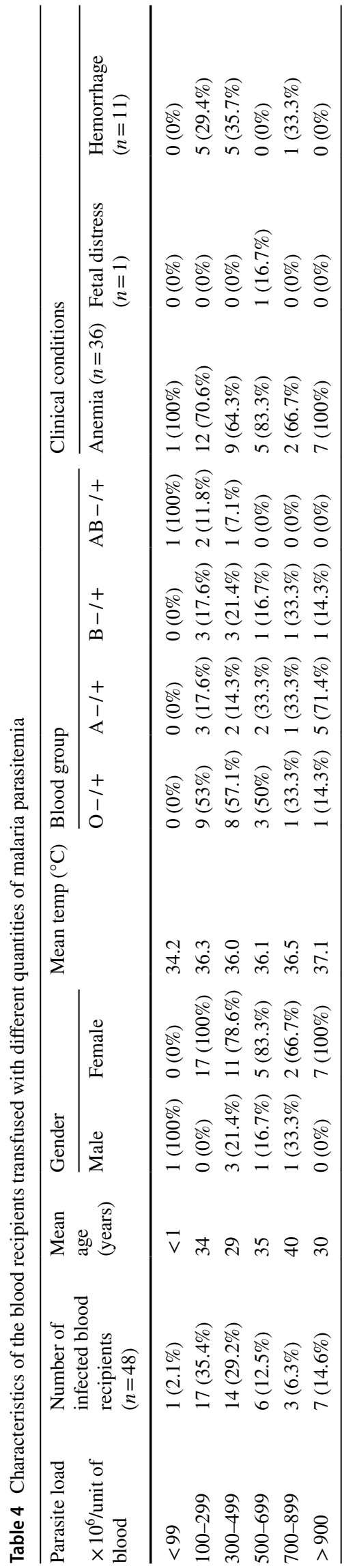


51 and 60 years, and blood group $\mathrm{AB}$ negative, in spite of all of them receiving infected donor blood. Parasitemia was detected in the rest of the variables at different levels. Highest levels were observed in recipients aged 41 and 50 years (3316 parasites $/ \mu \mathrm{L}$ ), females (3044 parasites $/ \mu \mathrm{L}$ ), blood group AB positive ( 9940 parasites $/ \mu \mathrm{L}$ ), follow-up day 2 (4869 parasites $/ \mu \mathrm{L}$ ), and previously anemic patients (3075 parasites/ $\mu \mathrm{L}$ ). In spite of these observations, no significant associations were found between recipients' posttransfusion parasitemia and recipient variables (Table 5).

\section{Attributes of infected donor blood units that resulted in recipient parasitemia}

Infected donor blood units that resulted in the majority of the infected blood recipients developing malaria parasitemia were units that were stored at $4{ }^{\circ} \mathrm{C}$ just for a day (71.4\%), those of blood group O positive (50\%), and units with mean total parasitemia between 100 and 299 million parasites per unit of blood. On the other hand, relatively high recipient parasitemia was observed in recipients that were transfused with blood stored for over 5 days (5344 parasites/ $\mu \mathrm{L}$ ), infected blood of type AB positive ( 9940 parasites/ $\mu \mathrm{L})$, and donor blood with total parasitemia more than 900 million parasites (5308 parasites/ $\mu \mathrm{L}$ ). Notwithstanding the
Table 5 Parasitological outcome of recipients' follow-up

\begin{tabular}{|c|c|c|c|c|}
\hline Variables & $\begin{array}{l}\text { Negative } \\
n=17\end{array}$ & $\begin{array}{l}\text { Positive by mRDT } \\
n=23\end{array}$ & $\begin{array}{l}\text { Positive by } \\
\text { microscopy } \\
n=14\end{array}$ & Mean parasitemia $(/ \mu \mathrm{L})$ \\
\hline \multicolumn{5}{|c|}{ Age range (year) ${ }^{l}$} \\
\hline $0-1$ & $0(0 \%)$ & $1(4.3 \%)$ & $0(0 \%)$ & Not applicable \\
\hline $2-5$ & $0(0 \%)$ & $0(0 \%)$ & $0(0 \%)$ & Not applicable \\
\hline $6-10$ & $0(0 \%)$ & $1(4.3 \%)$ & $1(7.1 \%)$ & 960 \\
\hline $11-20$ & $2(11.8 \%)$ & $1(4.3 \%)$ & $0(0 \%)$ & Not applicable \\
\hline $21-30$ & $6(35.3 \%)$ & $12(52.2 \%)$ & $5(35.7 \%)$ & 3316 \\
\hline $31-40$ & $6(35.3 \%)$ & $2(8.7 \%)$ & $2(14.3 \%)$ & 1854 \\
\hline $41-50$ & $2(11.8 \%)$ & $4(17.4 \%)$ & $4(28.6 \%)$ & 3867 \\
\hline $51-60$ & $1(5.9 \%)$ & $0(0 \%)$ & $0(0 \%)$ & Not applicable \\
\hline$>60$ & $0(0 \%)$ & $2(8.7 \%)$ & $2(14.3 \%)$ & 1231 \\
\hline \multicolumn{5}{|l|}{ Gender $^{2}$} \\
\hline Male & $2(11.8 \%)$ & $4(17.4 \%)$ & $3(21.4 \%)$ & 1991 \\
\hline Female & $15(88.2 \%)$ & $19(82.6 \%)$ & $11(78.6 \%)$ & 3044 \\
\hline \multicolumn{5}{|l|}{ Blood group ${ }^{3}$} \\
\hline $\mathrm{O}-1+$ & $9(52.9 \%)$ & $6(26.1 \%)$ & $5(35.7 \%)$ & 1002 \\
\hline $\mathrm{A}-/+$ & $5(29.4 \%)$ & $8(34.8 \%)$ & $5(35.7 \%)$ & 2624 \\
\hline $\mathrm{B}-/+$ & $2(11.8 \%)$ & $5(21.7 \%)$ & $3(21.4 \%)$ & 3605 \\
\hline $\mathrm{AB}+$ & $1(5.9 \%)$ & $4(17.4 \%)$ & $1(7.1 \%)$ & 9940 \\
\hline \multicolumn{5}{|l|}{ Follow-ups } \\
\hline Day 2 & & $1(4.3 \%)$ & $1(7.1 \%)$ & 4869 \\
\hline Day 7 & & $6(26.1 \%)$ & $3(21.4 \%)$ & 2308 \\
\hline Day 14 & & $5(21.7 \%)$ & $3(21.4 \%)$ & 4238 \\
\hline Day 21 & & $4(17.4 \%)$ & $2(14.3 \%)$ & 2138 \\
\hline Day 28 & & $3(13.0 \%)$ & $2(14.3 \%)$ & 3752 \\
\hline Day 35 & & $4(17.4 \%)$ & $3(21.4 \%)$ & 818 \\
\hline \multicolumn{5}{|c|}{ Medical condition necessitating the blood transfusion ${ }^{4}$} \\
\hline Anemia & $11(64 / 7 \%)$ & $21(91.3 \%)$ & $12(85.7 \%)$ & 3075 \\
\hline Fetal distress & $0(0 \%)$ & $1(4.3 \%)$ & $1(7.1 \%)$ & 996 \\
\hline Hemorrhage & $6(35.3 \%)$ & $1(4.3 \%)$ & $1(7.1 \%)$ & 1521 \\
\hline
\end{tabular}

${ }^{1}$ Suspected TTM was not associated with age $\left(x^{2}=1.61, p=0.656\right)$

${ }^{2}$ Suspected TTM was not associated with gender $\left(x^{2}=0.31, p=0.587\right)$

${ }^{3}$ Suspected TTM was not associated with blood group $\left(x^{2}=0.39, p=0.941\right)$

${ }^{4}$ Suspected TTM was not associated with medical condition necessitating blood transfusion $\left(x^{2}=1.39\right.$, $p=0.497$ ) 
foregoing, the number of donor blood storage days, donor blood group, and infected donor blood total parasitemia did not associate with the frequency of detecting malaria parasitemia in infected blood recipients (Table 6).

\section{Discussion}

This study provides preliminary evidence of probable transfusion-transmitted malaria (TTM) among recipients of Plasmodium falciparum-infected donor blood. This baseline data is essential because Plasmodium sp. infection is common in blood donors and donor blood units, especially in donors from malaria endemic regions (Garba et al. 2016; AntwiBaffour et al. 2019; Schindler et al. 2019). This causes the presence of $P$. falciparum in donor blood units with possible transmission to blood recipients, if the contaminated blood is not excluded from clinical use (Olawumi et al. 2015). Individuals mostly at risk of TTM are blood recipients living in malaria nonendemic regions with partial or no anti-parasite immunity (Verra et al. 2018). It is in view of the foregoing that this study was done to assess malaria parasitemia in recipients of $P$. falciparum-infected donor blood.

It is reported herein that 14 out of 48 recipients of infected donor blood with microscopically detectable malaria parasites developed malaria parasitemia; hence, TTM is suspected in these blood recipients. Majority of the recipients with microscopically detectable malaria parasitemia received donor blood that were stored for only a day (71.4\%) and donor blood of group $\mathrm{O}$ rhesus $\mathrm{D}$ positive $(50 \%)$. Interestingly, even though the recipients received various quantities of malaria parasites, the majority of the post-transfusion infection was observed in recipients of parasites within the range 100-499 million parasites per unit of blood $(57.1 \%)$ compared to donor units of contaminating parasites of 500 million or more. It is not surprising to observe that blood stored for just a day yielded $P$. falciparum parasitemia in most of the recipients. This is because $P$. falciparum has been reported to remain intact for up to 28 days but viability is lost after 14 days storage at $4{ }^{\circ} \mathrm{C}$ (Chattopadhyay et al. 2011). However, it was intriguing to observe that mean parasitemia in the donor blood was higher in 2-5 days of storage compared to mean levels after storage for a day. Although marginally, this observation may be due to the vast differences in the baseline parasitemia levels (which was not possible to determine in this study since the remainder of donor blood was used for this study). However, parasitemia was significantly reduced in donor blood stored for over 5 days. Reduction in parasitemia after 5 days of blood storage at $4{ }^{\circ} \mathrm{C}$ has previously been reported (Chattopadhyay et al. 2011). It is currently unknown why transfusion of high quantities of parasites per unit of blood did not correspond to high infectivity in the recipients. Regardless of that, most of the recipients with suspected TTM were females $(87.5 \%)$, recipients with blood group O $(53.1 \%)$, and anemic recipients $(65.6 \%)$. Though, post-transfusion parasitemia did not statistically associate with these variables.

Table 6 Characteristics of infected donor blood transfused to recipients with detectable parasites on follow up

\begin{tabular}{|c|c|c|c|c|}
\hline Parameter & $\begin{array}{l}\text { Mean total parasitemia in } \\
\text { transfused blood }\end{array}$ & $\begin{array}{l}\text { Number of recipients with } \\
\text { malaria parasitemia } n=14\end{array}$ & $x^{2}(p$-value $)$ & $\begin{array}{l}\text { Mean recipient parasite } \\
\text { count }(/ \mu \mathrm{L}) \text { on follow-up } \\
\text { testing }\end{array}$ \\
\hline Storage days & & & $0.44(0.801)$ & \\
\hline $1(n=37)$ & $845,929,080$ & $10(71.4 \%)$ & & 2694 \\
\hline $2-5(n=7)$ & $939,542,300$ & $2(14.3 \%)$ & & 2272 \\
\hline$>5(n=4)$ & $296,303,200$ & $2(14.3 \%)$ & & 5344 \\
\hline Blood group ${ }^{a}$ & & & $0.07(0.999)$ & \\
\hline $\mathrm{O}+(n=24)$ & $1,062,909,957$ & $7(50 \%)$ & & 2068 \\
\hline $\mathrm{O}-(n=4)$ & $715,022,100$ & $1(7.1 \%)$ & & 1521 \\
\hline $\mathrm{A}+(n=9)$ & $597,028,267$ & $3(21.4 \%)$ & & 3859 \\
\hline $\mathrm{B}+(n=7)$ & $322,101,200$ & $2(14.3 \%)$ & & 2080 \\
\hline $\mathrm{AB}+(n=3)$ & $340,300,000$ & $1(7.1 \%)$ & & 9940 \\
\hline Parasite count range ${ }^{\mathrm{b}}$ & & & $1.67(0.795)$ & \\
\hline $100-299(n=17)$ & $230,005,840$ & $5(35.7 \%)$ & & 1653 \\
\hline $300-499(n=14)$ & $437,165,867$ & $3(21.4 \%)$ & & 4797 \\
\hline $500-699(n=6)$ & $547,063,200$ & $1(7.1 \%)$ & & 996 \\
\hline $700-899(n=3)$ & $758,429,050$ & $2(14.3 \%)$ & & 1299 \\
\hline$>900(n=7)$ & $2,135,176,967$ & $3(21.4 \%)$ & & 5308 \\
\hline
\end{tabular}

${ }^{\text {a }}$ The blood groups summed up to 47 because B negative did not result in any recipient parasitemia; ${ }^{\mathrm{b}}$ frequency of parasite count did not add 48 because parasitemia less than 100 million did not result in recipient follow-up up parasitemia 
In contrast to the findings in this study, males have been reported to be more susceptible to infectious diseases than females (Klein 2000; Altamimi et al. 2020; Bunders and Altfeld 2020; Migliore et al. 2021). The only attributable reason to this observation of the high incidence of $P$. falciparum infection in female blood recipients was that disproportionately more female blood recipients than male blood recipients were encountered during the study. Despite the lack of association with post-transfusion parasitemia, there is an attempt to provide reasons why posttransfusion malaria parasitemia was disproportionately higher in anemic patients. This observation could be due to compromised immunity associated with anemia. Hassan et al. 2016 reported significantly lower IgG levels, IL-6, and phagocytic activity in anemic patients. Similarly, it has also been established that anemia, especially iron deficiency anemia, increases susceptibility to infectious diseases (Beard 2001). Individuals with blood groups A and B were found to be highly susceptible to P. falciparum infection in several studies (Panda et al. 2011; Afoakwah et al. 2016). However, in this study, the frequency of incidence of $P$. falciparum infection was found to be high in blood group $\mathrm{O}$. This could be due to the high number of blood recipients of blood group O (49.5\%). Notwithstanding the foregoing, the mean parasitemia in blood recipients of blood group $\mathrm{O}$ was less than that in recipients of group A (2068 vs. 3859 parasites/ $\mu \mathrm{L}$ of blood). This confirms that blood group A is very susceptible to $P$. falciparum infection than blood group O (Panda et al. 2011; Afoakwah et al. 2016).

Post-transfusion parasitemia was reported in all follow-up time points, with a slight majority of them being on followup days 7,14 , and 35 . This could mean that $P$. falciparum established infection as soon as transfusion was completed while others delayed until after a month. This observation could be possible since, unlike $P$. falciparum transmission through mosquito bites, infected blood transfusions directly release the malaria parasite in the recipient's bloodstream (Garraud 2006) and within 8-29 days later, which is the incubation period for TTM (Dover and Schultz 1971), TTM could occur. For this reason, detection of malaria parasites up to 35 days is not impossible. Because as few as 10 infected red blood cells have been shown to be infectious (Verra et al. 2018), hence, transfusion of a mean parasitemia of over 600 million parasites in an infected donor blood could be potentially infectious as observed in this study.

Except for donor blood group B, negative post-transfusion parasitemia was observed in all donor blood variables (blood group type, number of days of storage, and levels of parasite contamination). Similarly, in all age groups, gender, blood groups, and clinical conditions of the recipients, TTM was suspected. This implies that donor P. falciparum contamination could potentially be transmitted to all categories of blood recipients. It was also observed that TTM was not suspected in all infected blood recipients; therefore, it is important to identify factors that render some blood recipients susceptible to TTM.

Throughout the follow-up period, none of the infected blood recipients developed body temperatures above $37.1^{\circ} \mathrm{C}$ (range: $34.2-37.1^{\circ} \mathrm{C}$ ). The mean parasitemia recorded in the infected blood recipients was 3012 parasites/ $\mu \mathrm{L}$ of blood (range: 746-9940). On questioning, none of them reported any symptoms associated with symptomatic malaria. Even though these recipients could be asymptomatic per Ramaswamy et al. (2020) definition, they were immediately referred to the nearest health facility for further assessment and subsequent management.

It must be emphasized that the $P$. falciparum infections detected in infected blood recipients may not necessarily be due to the parasites present in the donor blood units. Once the blood recipients live in a malaria endemic district (2017, prevalence of malaria in the study district was 32.9\%) (Ndong et al. 2019), new infections and/or recrudescence of previous infections is a possibility. Even though all infected blood recipients were negative by $\mathrm{mRDT}$, the technique has been found not to be able to detect $P$. falciparum antigens in infections with parasitemia less than 50 parasites $/ \mu \mathrm{L}$ of blood (Wongsrichanalai et al. 2007; Okell et al. 2009). Therefore, it is important to determine the genetic relatedness of the pre- and post-transfusion parasites to confirm whether or not TTM has occurred.

\section{Conclusion}

This study provides baseline data on TTM in Ghana. Although the prevalence of suspected TTM was reported to be $3.2 \%$ (14/440), future studies should further establish the genetic relatedness of the implicated parasites. Furthermore, factors that make blood recipients vulnerable to TTM must also be established.

Abbreviations CRBC: Concentrated red blood cells; mRDT: Malaria rapid diagnostic test kit; mRDT: Malaria rapid diagnostic testing; NGH: Nsawam Government Hospital; Rh: Rhesus; TTM: Transfusiontransmitted malaria

Acknowledgements The authors are grateful to the Management of National Malaria Control Programme, especially James Frimpong (Deputy Programme Manager) and Alexander Asamoah (the Diagnostic Focal Person), for providing malaria RDT kits for the study. We are also grateful to Stephen Obeng and Ebenezer Owusu Siaw for their immense support during the recipient follow-up phase of the study. Finally, we are thankful to the staff and management of Nsawam Government Hospital and in particular Anita Kwekwor Eyo for accepting us into their working space for the purposes of this study.

Author contribution Conceptualization, study design, and coordination of the study-EA, GK-N, DOA. Field work and post-transfusion 
sample collection—JA, MDP, IT. Data collection and laboratory analysis-JA, IT, MDP. Data curation and analysis-JA, EA, JAf, DOA. Literature review and drafting of manuscript-JA, IT, MDP, EA. All authors read and approved the manuscript.

Data availability Datasets generated and analyzed in this study are available in the Harvard data verse repository (https://doi.org/10.7910/ DVN/8RMKVN). However, a request for the data can be obtained from the corresponding authors on reasonable request.

\section{Declarations}

Ethics approval Ethical approval for the study was granted by the Ghana Health Service Ethics Review Committee (approval ID: GHSERC-004/12/19). Written consent was obtained from all participating blood recipients. All laboratory results were communicated to study participants and appropriate action was taken promptly.

Consent for publication Written informed consent was obtained from each blood recipient for publication of their data.

Competing interests The authors declare no competing interests.

\section{References}

Abdullah S, Karunamoorthi K (2016) Malaria and blood transfusion: major issues of blood safety in malaria-endemic countries and strategies for mitigating the risk of Plasmodium parasites. Parasitol Res 115(1):35-47. https://doi.org/10.1007/s00436-015-4808-1

Ademolue TW, Awandare GA (2018) Evaluating antidisease immunity to malaria and implications for vaccine design. Immunology 153(4):423-434. https://doi.org/10.1111/imm.12877

Afoakwah R et al (2016) Relative Susceptibilities of ABO Blood Groups to Plasmodium falciparum Malaria in Ghana. Adv Hematol 2016:1-4. https://doi.org/10.1155/2016/5368793

Alemu G, Mama M (2018) Asymptomatic malaria infection and associated factors among blood donors attending Arba Minch blood bank, Southwest Ethiopia. Ethiop J Health Sci 28(3):315. https:// doi.org/10.4314/ejhs.v28i3.9

Altamimi A et al (2020) Demographic variations of MERS-CoV infection among suspected and confirmed cases: an epidemiological analysis of laboratory-based data from Riyadh Regional Laboratory. Biomed Res Int 2020:1-6. https://doi.org/10.1155/2020/ 9629747

Aninagyei E, Tetteh CD et al (2020a) Efficacy of Artemether-Lumefantrine on various Plasmodium falciparum Kelch 13 and Pfmdr1 genes isolated in Ghana. Parasite Epidemiol Control 11:e00190. https://doi.org/10.1016/j.parepi.2020.e00190

Aninagyei E et al (2020b) Elevated IL-12, TNF- $\alpha$, and TNF- $\alpha / \mathrm{IL}-10$ ratios in Stored Plasmodium falciparum-infected whole blood: implications for safe haemotransfusion. J Immunol Res 2020. https://doi.org/10.1155/2020/9394585

Aninagyei E et al (2021) Effect of Asymptomatic Plasmodium falciparum parasitaemia on platelets thrombogenicity in blood donors. Indian J Hematol Blood Transfus. https://doi.org/10.1007/ s12288-020-01390-w

Antwi-Baffour S et al (2019) The incidence of malaria parasites in screened donor blood for transfusion. Malar Res Treat 2019:1-6. https://doi.org/10.1155/2019/1457406

Beard JL (2001) Iron biology in immune function, muscle metabolism and neuronal functioning. J Nutr 131(2):568S-580S. https://doi. org $/ 10.1093 / \mathrm{jn} / 131.2 .568 \mathrm{~S}$
Bunders MJ, Altfeld M (2020) Implications of sex differences in immunity for SARS-CoV-2 pathogenesis and design of therapeutic interventions. Immunity 53(3):487-495. https://doi.org/ 10.1016/j.immuni.2020.08.003

Chattopadhyay R, Majam VF, Kumar S (2011) Survival of Plasmodium falciparum in human blood during refrigeration. Transfusion 51(3):630-635. https://doi.org/10.1111/j.1537-2995.2010. 02872.x

Cox FE (2010) History of the discovery of the malaria parasites and their vectors. Parasit Vectors 3(1):5. https://doi.org/10.1186/ 1756-3305-3-5

Dhiman S (2019) Are malaria elimination efforts on right track? An analysis of gains achieved and challenges ahead. Infect Dis Poverty 8(1):14. https://doi.org/10.1186/s40249-019-0524-x

Dover AS, Schultz MG (1971) Transfusion-induced malaria. Transfusion 11(6):353-357. https://doi.org/10.1111/j.1537-2995. 1971.tb04429.x

Faruk JA, Ogunrinde GO, Mamman AI (2017) Observation of blood donor-recipient malaria parasitaemia patterns in a malaria endemic region. J Trop Med 2017:1-5. https://doi.org/10.1155/ $2017 / 7149261$

Garba D et al (2016) Prevalence of malaria parasites among blood donors in Kaduna, Nigeria. Int J Res Med Sci: 2112-2119. https://doi.org/10.18203/2320-6012.ijrms20161770

Garraud O (2006) Mechanisms of transfusion-linked parasite infection. Transfus Clin Biol 13(5):290-297. https://doi.org/10. 1016/j.tracli.2006.11.005

Hassan TH et al (2016) Impact of iron deficiency anemia on the function of the immune system in children. Medicine 95(47):e5395. https://doi.org/10.1097/MD.0000000000005395

Jersild C, Hafner V (2017) Blood transfusion services. In: International Encyclopedia of Public Health. Elsevier, p 247-253. https://doi.org/10.1016/B978-0-12-803678-5.00037-0

Kitchen A, Mijovic A, Hewitt P (2005) Transfusion-transmitted malaria: current donor selection guidelines are not sufficient. Vox Sang 88(3):200-201. https://doi.org/10.1111/j.1423-0410. 2005.00610.x

Klein SL (2000) The effects of hormones on sex differences in infection: from genes to behavior. Neurosci Biobehav Rev 24(6):627638. https://doi.org/10.1016/S0149-7634(00)00027-0

Migliore L, Nicolì V, Stoccoro A (2021) Gender specific differences in disease susceptibility: the role of epigenetics. Biomedicines 9(6):652. https://doi.org/10.3390/biomedicines9060652

Ndong IC et al (2019) Prevalence of asymptomatic malaria parasitaemia following mass testing and treatment in Pakro sub-district of Ghana. BMC Public Health 19(1):1622. https://doi.org/10. 1186/s12889-019-7986-4

Okell LC et al (2009) Submicroscopic Infection in Plasmodium falciparum -endemic populations: a systematic review and metaanalysis. J Infect Dis 200(10):1509-1517. https://doi.org/10. 1086/644781

Oladeinde BH et al (2014) Asymptomatic malaria among blood donors in Benin City Nigeria. Iran J Parasitol 9(3):415-22

Olawumi $\mathrm{HO}$ et al (2015) Malaria parasitaemia among blood donors in Ilorin, Nigeria. Afr J infect Dis 9(1):10-3. https://doi.org/10. 4314/ajid.v9i1.3

Owusu-Ofori A, Gadzo D, Bates I (2016) Transfusion-transmitted malaria: donor prevalence of parasitaemia and a survey of healthcare workers knowledge and practices in a district hospital in Ghana. Malar J 15(1):234. https://doi.org/10.1186/ s12936-016-1289-3

Panda AK et al (2011) Association of ABO blood group with severe falciparum malaria in adults: case control study and meta-analysis. Malar J 10(1):309. https://doi.org/10.1186/ 1475-2875-10-309 
Ramaswamy A et al (2020) Asymptomatic malaria carriers and their characterization in hotpops of malaria at Mangalore. Trop Parasitol 10(1):24-28. https://doi.org/10.4103/tp.TP_71_18

Schindler T et al (2019) Molecular monitoring of the diversity of human pathogenic malaria species in blood donations on Bioko Island, Equatorial Guinea. Malar J 18(1):9. https://doi.org/10. $1186 / \mathrm{s} 12936-019-2639-8$

Tsehay S et al (2020) 'Blood transfusion-transmissible malaria and its cost analysis in Hawassa regional blood bank, Southern Ethiopia. SAGE Open Medicine 8:205031212093693. https://doi.org/10. $1177 / 2050312120936930$

Verra $\mathrm{F}$ et al (2018) A systematic review of transfusion-transmitted malaria in non-endemic areas. Malar J 17(1):36. https://doi.org/ 10.1186/s12936-018-2181-0

Vitello DJ et al (2015) Blood density is nearly equal to water density: a validation study of the gravimetric method of measuring intraoperative blood loss. J Vet Med 2015:1-4. https://doi.org/10. $1155 / 2015 / 152730$

WHO (2018) World Health Organization. World malaria report 2018. Geneva: World Health Organization; 2018

Wongsrichanalai C et al (2007) A review of malaria diagnostic tools: microscopy and rapid diagnostic test (RDT). Am J Trop Med Hygi 77(6 Suppl), pp. 119-27. Available at: http://www.ncbi.nlm.nih. gov/pubmed/18165483

Publisher's note Springer Nature remains neutral with regard to jurisdictional claims in published maps and institutional affiliations. 